\title{
Clinical Presentation of a Confusing and Atypical Vegetative Dermatosis
}

\author{
Selma Benkirane *, Sara Elloudi, Aida Oulehri, Zakia Douhi, Hanane BayBay, Fatima Zahra Mernissi \\ Department of Dermatology, University Hospital Hassan II, Fez, Morocco
}

*Corresponding author: Selma Benkirane, Department of Dermatology, University Hospital Hassan II, Fez, Morocco.

Received date: February 07, 2020; Accepted date: February 10, 2020; Published date: February 21,2020

Citation: Benkirane S, Elloudi S, Oulehri A, Douhi Z, BayBay H. (2020) Clinical Presentation of a Confusing and Atypical Vegetative Dermatosis. Journal of Clinical Case Reports and Studies, 1(1): Doi:10.31579/ 2690-8808/003

Copyright: (C) 2020 Selma Benkirane, This is an open access article distributed under the Creative Commons Attribution License, which permits unrestricted use, distribution, and reproduction in any medium, provided the original work is properly cited.

\section{Introduction}

The vegetative pemphigus is the rarest variety of pemphigus. It only represents 1 to $2 \%$ of cases. It is characterized by damage to the folds and a vegetative appearance of the lesions. Its pathophysiology has not yet been elucidated. The diagnosis is clinically suspected and confirmed by histology and direct and indirect immunofluorescence. Treatment is based on general corticosteroid therapy with a rapid and favorable response.

We present through this observation a case of vegetative pemphigus which has been confused with many vegetative dermatoses.

\section{Case report}

This is a 67-year-old diabetic hypertensive, and followed for hepatitis C at the cirrhosis stage under Daclatasvir and Sofosbuvir, who for three months has had lesions in the mouth aggravated one week after taking treatment with a swelling of the right thumb extensive to the other toes of the left foot, secondarily associated with bullous lesions in the left sub mammary and pruritic genital area with a tingling sensation giving way to erosions. The examination on admission found a swelling of the right thumb with pus from pressure [Figure 1], the right big toe [Figure 2(A)] and the first 4 toes of the left foot, seat of an erosive plaque surmounted by pustules, and others embedded in the confluent dermis with exposure of the nail matrix at the level of the nails of the affected fingers [Figure 2 (B)], the presence also of erosive plaque with papillomatous vegetative surface at the level of the folds under mammary [Figure 3] and inguinal with extension to the perineal region [Figure 4 (A)] arriving to the anal region [Figure 4 (B)] with a negative Nikolsky sign, the presence of a lip herpes [Figure $5(\mathrm{~A})$ ], oral erosions and a bleeding crack tongue on contact [Figure 5 (B)]. Regarding the scalp, a cutis gyrata was noted with scattered erosions topped with mellic crusts with pus [Figure 6], the rest of the examination was without particularities, the patient was in good general condition. Faced with this clinical picture, the diagnoses mentioned were a vegetative pemphigus, a vegetative herpes associated with a herpetic panaris, a vegetative pyoderma, a toxiderma and a pyoderma gangrenosum. Skin biopsy with direct immunofluorescence confirmed the diagnosis of vegetative pemphigus. The Neumann type was selected and corticosteroid therapy at $2 \mathrm{mg} / \mathrm{kg} /$ day was started associated with Azathioprine, the evolution was marked by a clinical improvement of the lesions after 01 month [Figure 7].

\section{Discussion}

Vegetative pemphigus is a form of deep pemphigus that occurs in more than $80 \%$ of cases during the fourth decades. Our patient had signs related to both forms: Neumann and Hallopeau with damage to the oral cavity, lips, damage to the scalp and nails. The pathophysiology of the vegetative character of lesions is not completely understood. It would involve local (occlusion, maceration and bacterial superinfection in the folds) and general (cytokines responsible for cell proliferation and eosinophil chemotaxis) factors [1]. The diagnosis is based on histology and on direct immunofluorescence as for indirect immunofluorescence, antibodies to intercellular substance are demonstrated in $80 \%$ of cases mainly directed against desmogleins 1 and 3 [2]. Treatment involves corticosteroids and immunosuppressants. The subacute course, the installation after taking a drug and the herpetic superinfection were confusing but the clinic, the histology and the direct immunofluorescence made it possible to rectify the diagnosis in our patient.

\section{Conclusion}

When faced with a multifocal vegetative dermatosis in the context of immunosuppression, a vegetative pemphigus should be sought. This form affects elderly patients with a clear female predominance. An early diagnosis allows to restore a rapid treatment marked by a favorable evolution under corticotherapy. Regular and prolonged monitoring of these patients is essential. 


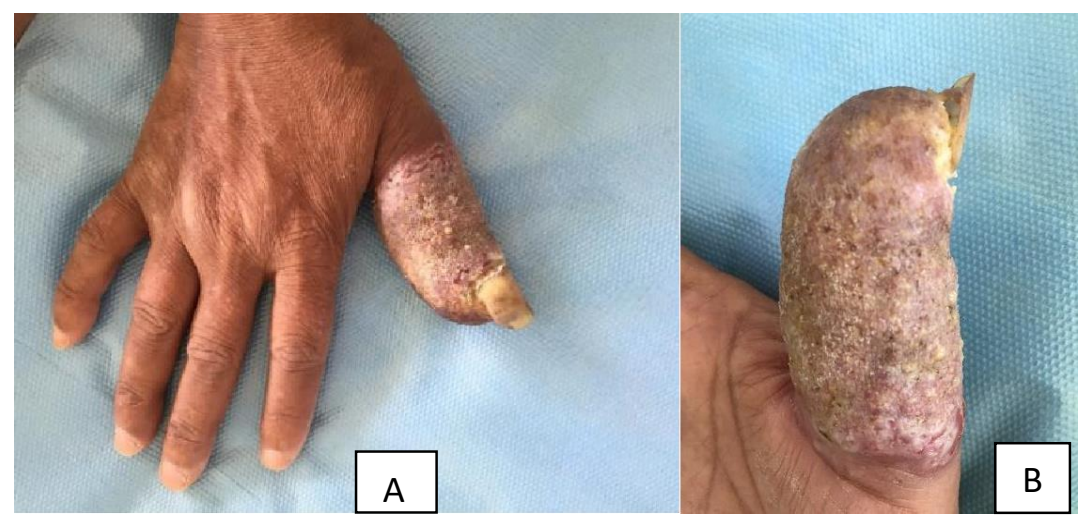

Figure 1: Eroded, swollen plaques taking the anterior (A) and posterior (B) sides of the right thumb with a vegetative surface, with pus from pressure.

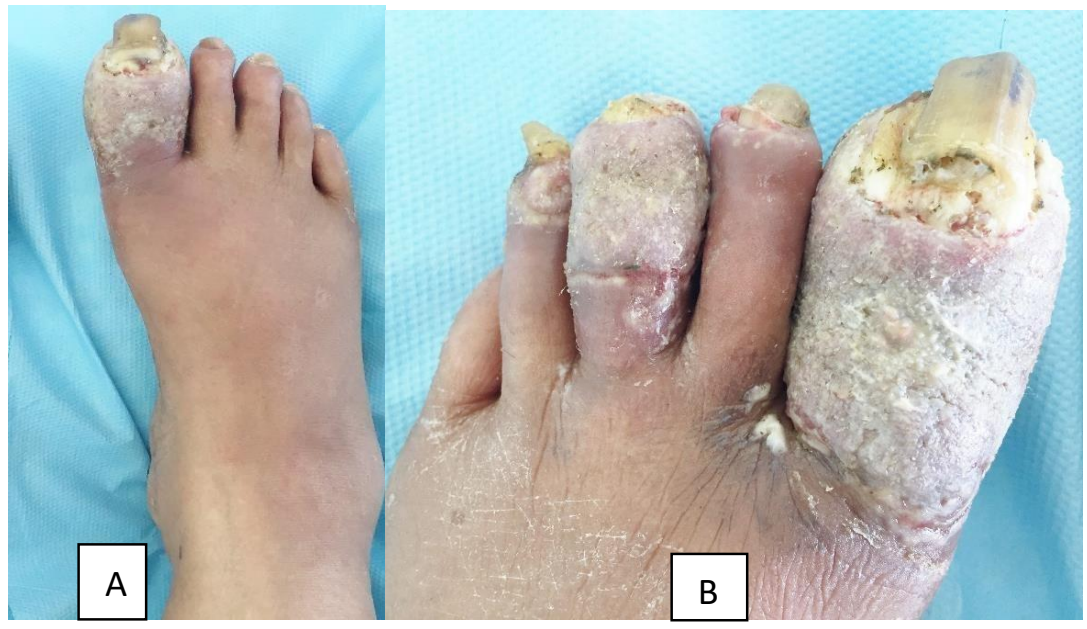

Figure 2: Affection of the big toe of the right foot (A) and the first 4 toes of the left foot (B), seat of a vegetative erosive plaques surmounted by pustules with exposure of the matrix nail in the affected fingernails.

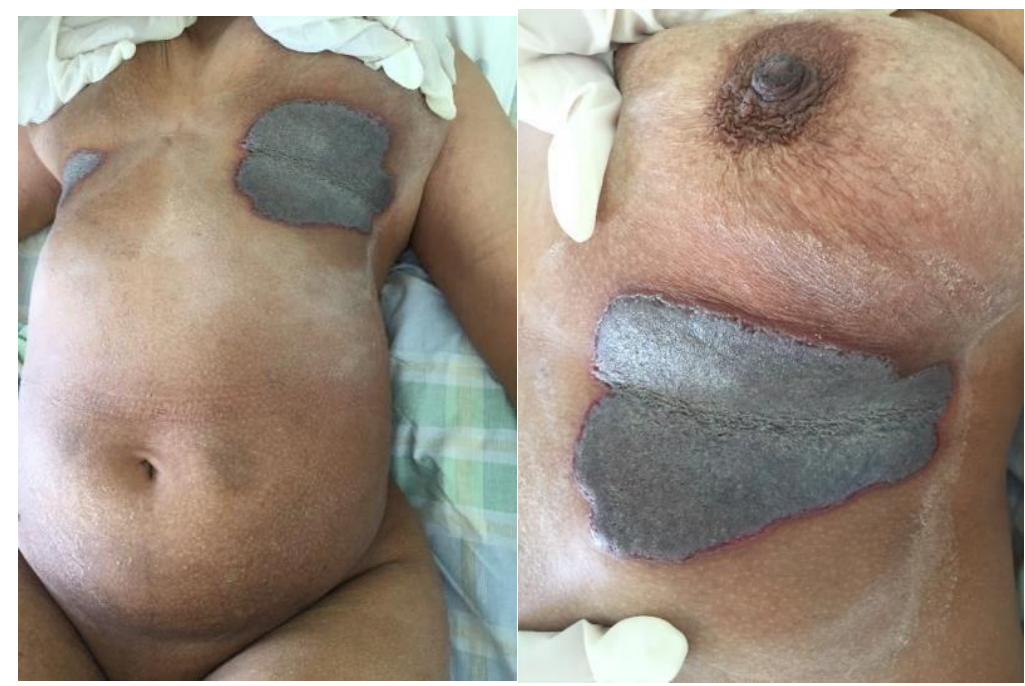

Figure 3: Well limited erosive plaques of variable size with papillomatous vegetative surface at the level of the breast folds. 

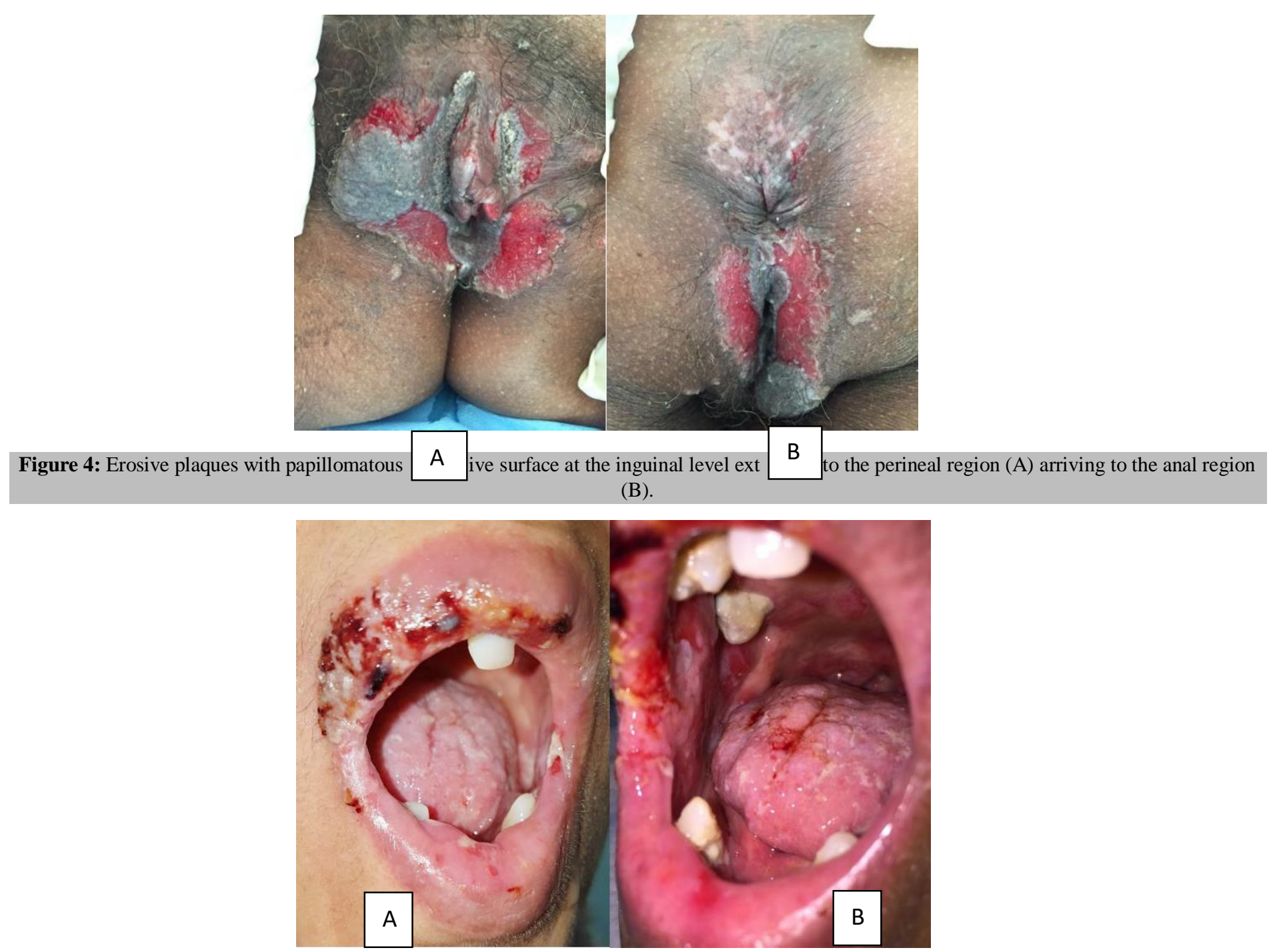

Figure 5: Presence of lip herpes (A), oral erosions and a crack tongue (B).

\footnotetext{
Figure 6: Presence of a cutis gyrata on the scalp with multiple erosions topped by meliceric crusts with pus.
} 

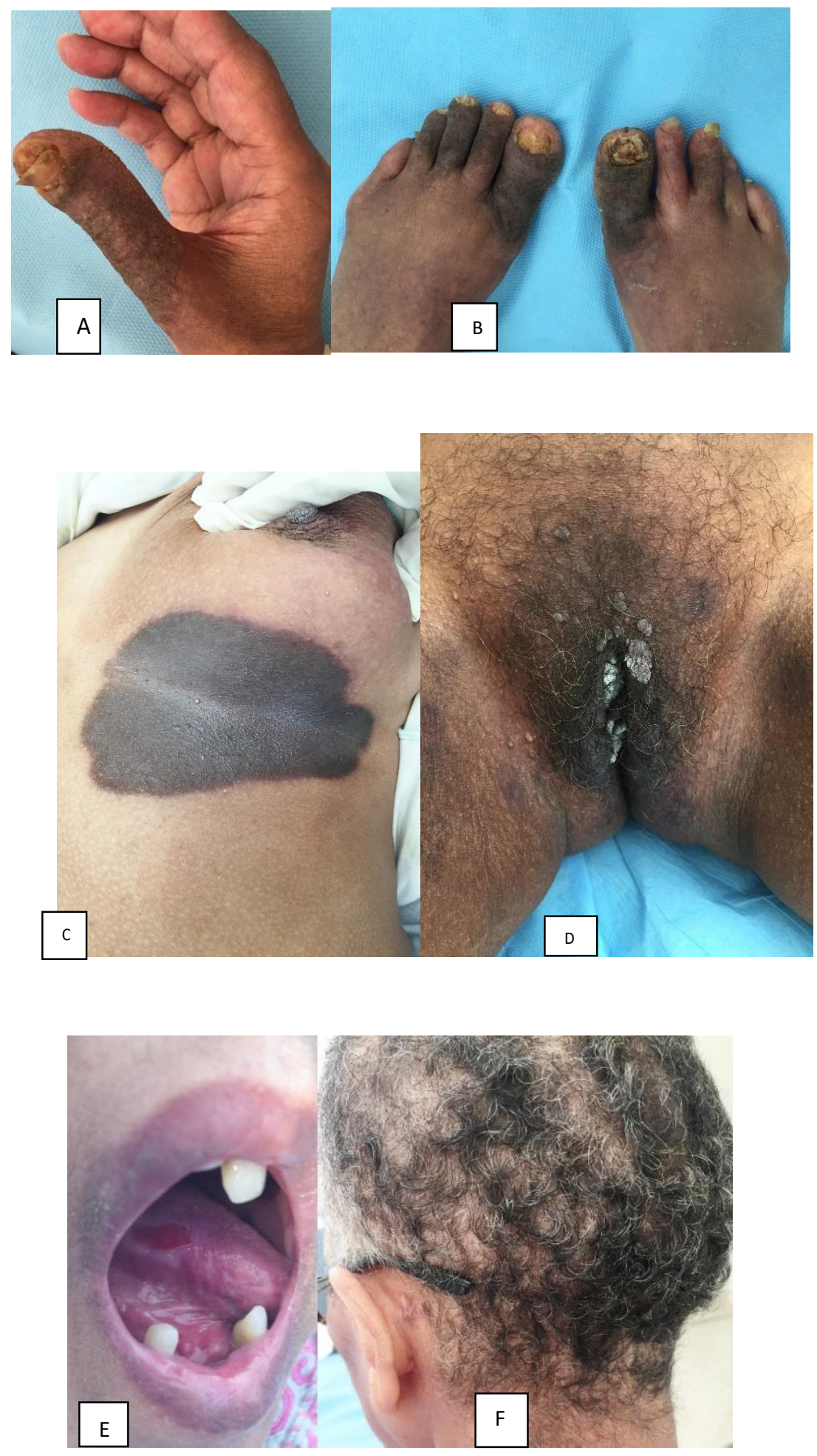

Figure 7: Clinical improvement of lesions of the thumb (A) of the toes (B) of the sub-mammary fold (C) of the genital area (D) of the oral mucosa $(\mathrm{E})$ and the scalp $(\mathrm{F})$ after 1 month of treatment. 


\section{Conflicts of interest}

Author declares that there is no conflict of interest

\section{References:}

1. Monshi B et al. (2010). Pemphigus vegetans: immunopathological findings in a rare variant of pemphigus vulgaris. J Dtsch Dermatol Ges, 8(3): $179-89$

2. Cozzani E et al. (2007). Pemphigus vegetans neumann type with antidesmoglein and anti-periplakin autoantibodies. Eur $\mathrm{J}$ dermatol, 17 (6):530-v
This work is licensed under Creative Commons Attribution 4.0 License

\section{To Submit Your Article Click Here: Submit Article}

DOI:10.31579/ccrs/2020/003

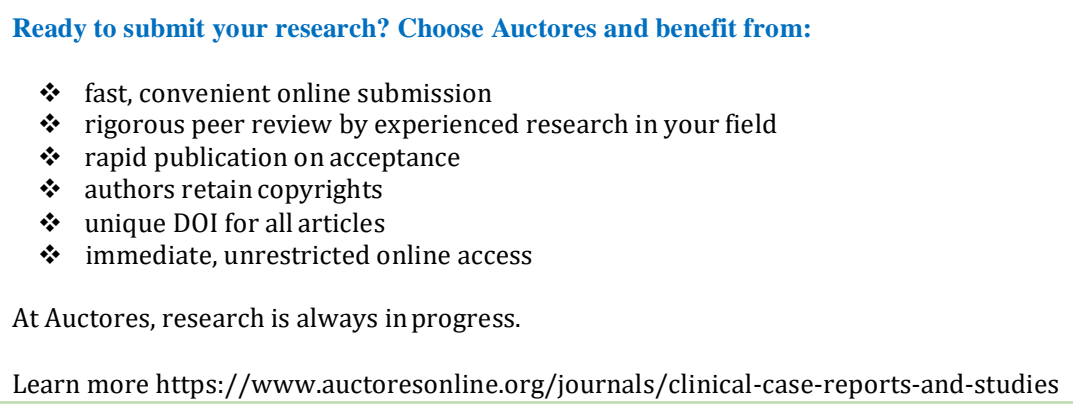

